\title{
PLC Based Load Sharing of Transformers
}

\author{
Iqra Rana, Murtaza Ali, Faheem Shafeeque Channar, Munsif Ali, Mustafa \\ Memon \\ Department of Electrical Engineering, Mehran University of Engineering \& \\ Technology, Jamshoro, 76062, Pakistan \\ ranaiqra640@gmail.com
}

\begin{abstract}
The transformer is very expensive and bulky power system equipment. It runs and feed the load for 24 hours a day. Sometimes the load on the transformer unexpectedly rises above its rated capacity in that situation the load on the transformer increases and it will be overloaded and current will increase and cause overheating which in results damage the insulation of transformer. That insulation failure resulting in interruption of power supply. The common problems which transformer face is overloading voltage fluctuations and heating effect. It takes lot of time to fix the transformer so that a device need to be introduced a device which would help in automatically sharing of these over voltages. We will try to build an automated transformer sharing system in this project where the transformer current is confined to auxiliary transformer and automatically enters system. There are three transformers working as sources in this project, initially when the main switched ON the load that time load will be shared through the first transformer but when the load on first transformer suddenly increase above its reference value then immediately second transformer connected parallel with first transformer automatically through PLC by busing relay circuit.
\end{abstract}

\section{Keywords}

Programmable Logic Controller (PLC), Relay,Transformer, Load, Interruption

\section{Introduction}

One of the essential factor that lay the foundation for social and economic growth of country is electrical energy. The government and community have controversial feedbacks regarding the problem. According to some people it is due to rapid growth of country and some contend that it has to do with failure of aged and transmission and distribution lines of power transformers (Nebey, 2020). Losses of the power system are also increased by the occurrence of faults, so faults should be removed at the earliest and corrective measures for example to isolate the fault must be considered. There are very common problems with overloading, voltage fluctuations and heating effects. The transformer repair time is very long and needs a lot of money. The primary duty is to safeguard the transformer against overload. Owing to overloading, the secondary winding becomes overheated because of burning. So, we reduce the extra load for the safety of the transformer.

This issue is solved by linking another transformer by relay in parallel with the main transformer (Nebey, 2020). The PLC is designed to verify the overloading of the first transformer and, if this condition occurs, the second transformer is automatically connected parallel to the first transformer and the load is shared. There are three transformers working as sources in this project. Initially, when the main switches on the load, the time load will be shared by the first transformer, but when the load on the first transformer unexpectedly rises past its reference value, the second transformer, connected parallel to the first transformer, will be automatically connected through the PLC by busting the relay circuit (Suryawanshi et al., 2019).

\section{Methodology}

Figure 1 shows the block diagram of PLC based load sharing of transformers 


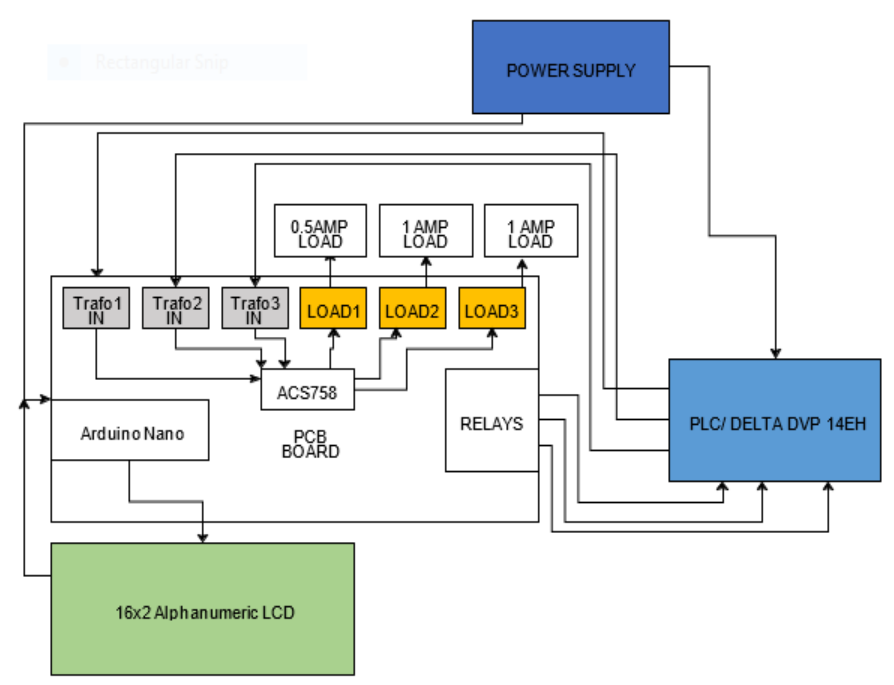

Figure 1. Block Diagram of Proposed PLC Based Load Sharing of Transformers

The Fig. 1 shows the block diagram The key component is PLC, according to above block diagram (Suryawanshi et al., 2019). Supply from the utility side of $220 \mathrm{~V}$ to the PLC is given. Current sensor (785) of 100A is used with Arduino Nano. This current sensor is connected in series with the loads of three transformers. Three relays which are in PCB board used to give input signal to PLC. Arduino cannot communicate with PLC directly because the PLC required the 24V DC input, relays are used to produce the desired power to solve this issue.

\subsection{Hardware Required For Prototype Model}

a. Relays

The relays used are $5 \mathrm{~V}$ or $6 \mathrm{~V}$. There are three relays used in this project which are on PCB. The PLC is trigger by the output of one of the relays. An electromagnetic relay consists of normally open and normally closed contacts.

b. PLC

In this project Delta PLC 14ES is used. The Programmable Logic Controller (PLC) is a digital device used in industry for automating different electro-mechanical processes. To provide the complete solution for different field applications these devices are connect with industrial automation products. Using PLC's to achieve the automation has the following advantages:

1) Flexible in nature

2) Easy to install and troubleshooting

3) Large contacts availability

4) Suitable for automation industries

5) Ease of maintenance

c. Transformers

In this project we have used the current sensor and three sources from extension and set the current sensor values according to the requirement of project which together with voltage gives the VA and share the load.

d. Power Supply

A $220 \mathrm{~V}$ power supply is used for this project.

e. Load

The load is used as Bulbs. Three bulbs are used in this project. Two bulbs of $200 \mathrm{~W}$ and one bulb of 100W. When only one bulb is ON then the transformer 1 is ON and when the second bulb will ON it means load is increased the transformer 2 which is connected in parallel with first transformer comes in operation with the $1^{\text {st }}$ transformer in same manner when bulb 3 is ON the transformer 3 comes in contact with transformer 1 and 2 and load is shared. 


\subsection{Flow Chart}

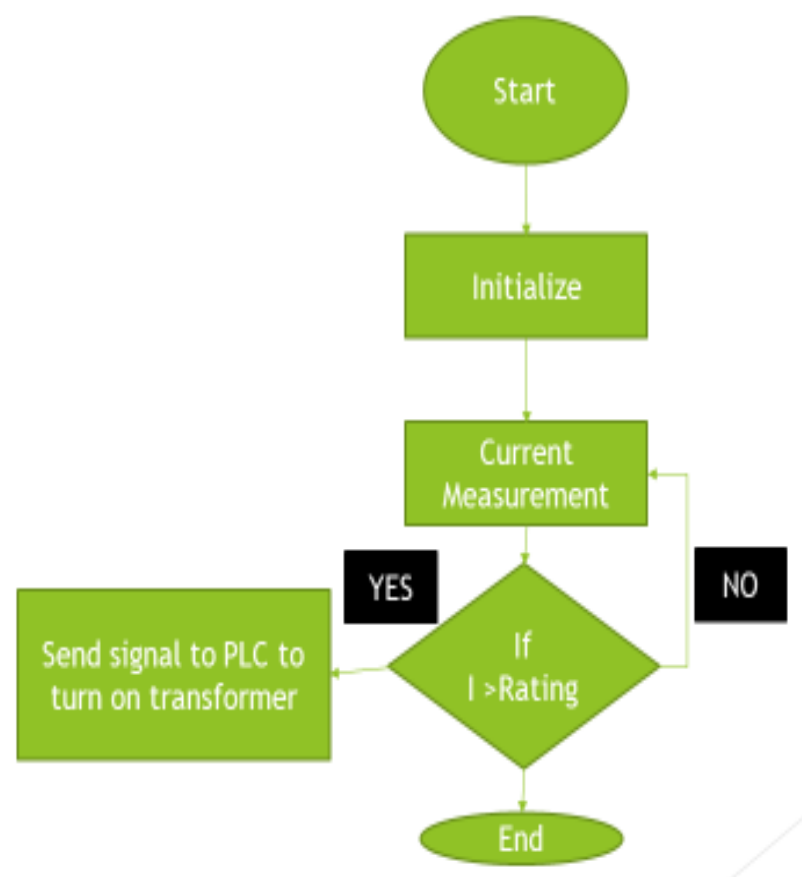

Figure 2. Flowchart Diagram

\subsubsection{Flowchart Description}

PLC based load sharing is advanced load sharing technique of transformers. A single transformer is supplied under normal conditions, and the remaining transformers are connected in parallel with each other (Shukla et al., 2017). In our project we used current sensor 785 of 100A with Arduino Nano and this current sensor connected in series with the loads of three transformers. Here we are using switches and current sensor which in result gives VA thus behaves like transformer. Relays are used to give input signal to PLC. Arduino will generate the signal that $X 0$ should be ON then it will send $24 \mathrm{~V}$ to PLC through relays. PLC check if $X 0$ input is high it will ON YO it means transformer 1 is $\mathrm{ON}$. Then current measurement will have done and if this measurement shows that current consumed is greater than the rating of first transformer then signal will go to PLC that it should ON the transformer 2 means high signal sent to X1 through relay and $\mathrm{Y} 1$ (transformer 2) will be ON. Load is connected with transformers which are connected in parallel hence load is shared. Now transformer 1 and transformer 2 together give source to load. Same condition is repeated in case of $3^{\text {rd }}$ transformer. When the load decreases the transformers will shut down respectively. XO is normally close because transformer will remain ON all the time (Kazmi et al., 2019).

\section{Results And Discussions} Hardware:

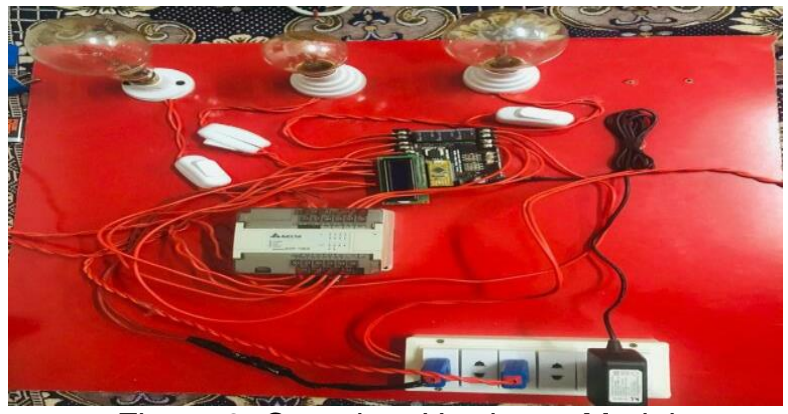

Figure 3. Complete Hardware Model 
Fig 3.1 shows that load 1 is ON means when (X0) load1 which is of $100 \mathrm{~W}$ is given then the output $\mathrm{YO}$ will $\mathrm{ON}$ means transformer $1 \mathrm{ON}$ which is having a rating of 110VA. Such that voltage $s$ from extension is $220 \mathrm{~V}$ and current is set $0.5 \mathrm{~A}$ from current sensor 785 .

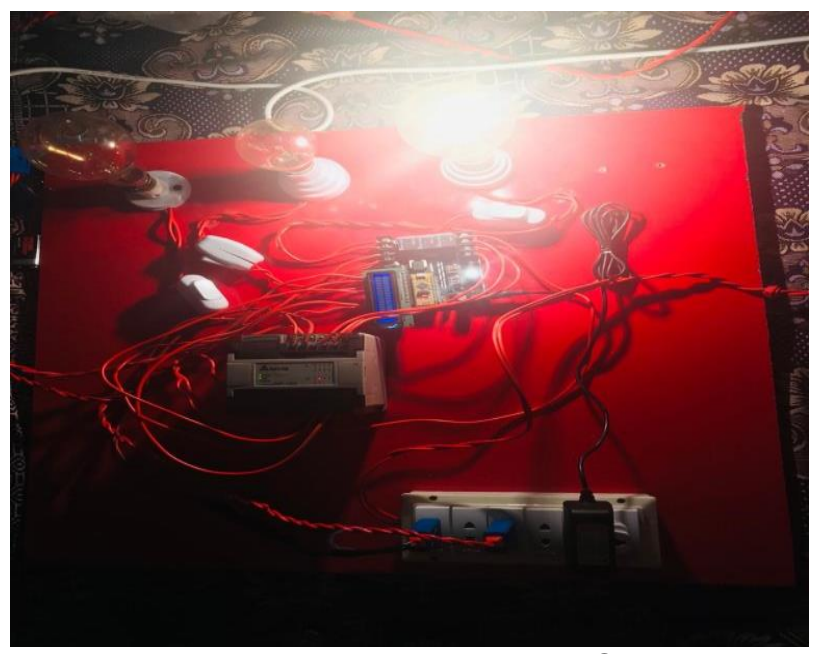

Figure 4.1. When load 1 is ON

Fig 4.2 shows that load 1 and 2 is ON means when (X1) load2 is of $200 \mathrm{~W}$ then the output $\mathrm{Y} 1$ will ON means transformer 2 having a rating of 220VA will ON which is in parallel with the first transformer. Such that voltages from extension is $220 \mathrm{~V}$ and current is set $1 \mathrm{~A}$ from current sensor 785 .

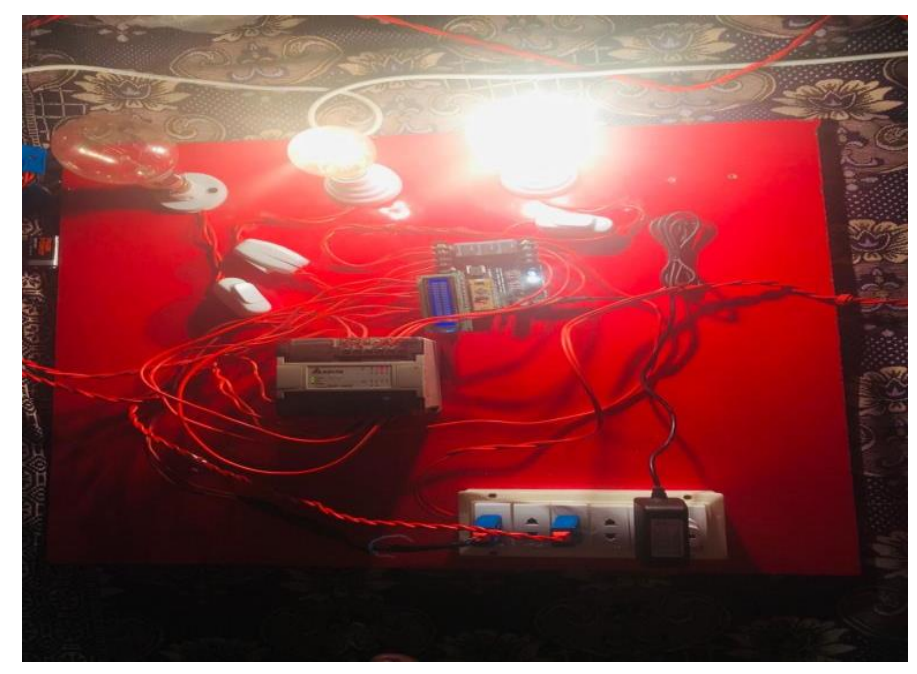

Figure 4.2 When load 1 and 2 are ON

Figure 4.3 shows that load 1,2 and 3 is ON means when (X2) load 3 is of $200 \mathrm{~W}$ then the output Y2 will ON means transformer 3 having a rating of 330VA will ON which is in parallel with the first and second transformer. Such that voltage $s$ from extension is $220 \mathrm{~V}$ and current is set $1.5 \mathrm{~A}$ from current sensor 785 . 


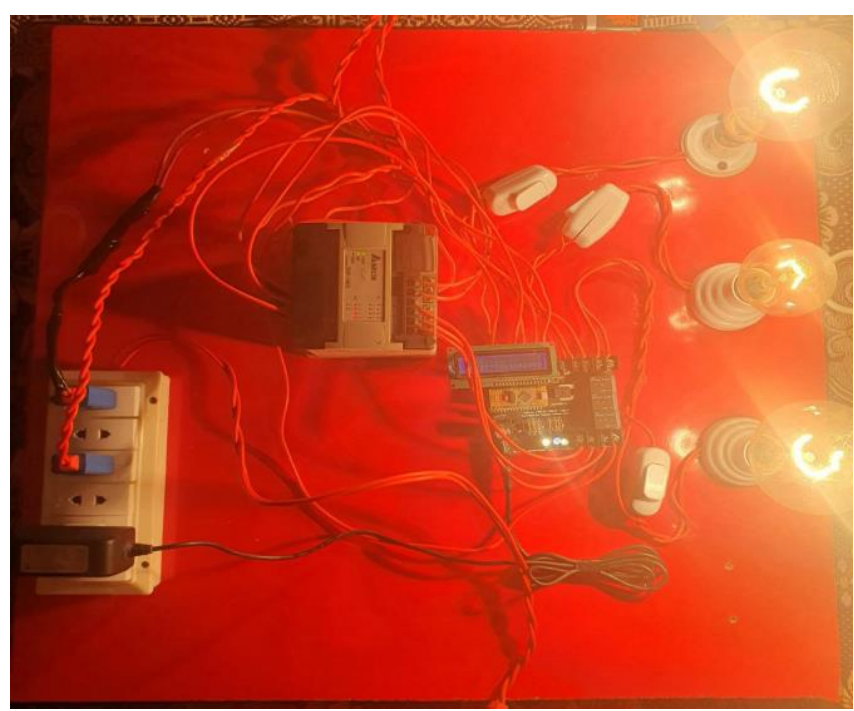

Figure 4.3 When load 1,2 and 3 are ON

\section{Conclusion}

This research is beneficial in offering a definite solution for automatic load sharing of transformers.

The "Automatic load sharing of transformers using PLC" work is successfully planned, tested and hardware is proposed to automatically share the load with the aid of changeover relay and PLC circuit for operation of three transformers in parallel. It prevents the main transformers from overloading and overheating, providing customers with an un-interrupted power supply of electricity.

Two or three transformers are coupled in parallel to the original transformer in order to provide a load that exceeds the rating of the original transformer. When the load on one transformer is greater than its capacity, the transformers are connected in parallel. The entire process can be regulated by a PLC. The efficiency improved with concurrent operation, rather than having a one larger unit, even the cost associated with the maintenance of the spars is lower when two transformers are connected in parallel.

During our project, the most important aspect was the analysis of load sharing between transformers. During, this time I was able to link the theoretical part to the practical part.

Table 1. Switching table

\begin{tabular}{|c|c|c|c|c|c|c|c|}
\hline Voltage & Amper & $\begin{array}{c}\text { sLoad } 1 \\
200 \mathrm{~W}\end{array}$ & $\begin{array}{l}\text { Load } \\
2 \\
100 \mathrm{~W}\end{array}$ & $\begin{array}{l}\text { Load } \\
3 \\
200 \mathrm{~W}\end{array}$ & $\begin{array}{c}\text { T.F } \\
1\end{array}$ & $\begin{array}{c}\text { T.F } \\
2\end{array}$ & $\begin{array}{c}\text { T.F } \\
3\end{array}$ \\
\hline $220 v$ & $0.5 \mathrm{~A}$ & ON & OFF & OFF & ON & OFF & OFF \\
\hline $220 v$ & $1 \mathrm{~A}$ & ON & ON & OFF & ON & ON & OFF \\
\hline $220 v$ & $1.5 \mathrm{~A}$ & ON & OFF & ON & ON & ON & ON \\
\hline
\end{tabular}

\subsection{Future Scope}

1) In particular, the future scope of this project lies in substations.

2) In substations, the operation of an additional transformer is needed to provide the extra load requirement, especially during peak hours.

3) In our project the transformers under critical loads are automatically connected. 
4) Therefore, there is no need for both transformers to work under regular loads, particularly during off-peak hours. Power is therefore shared intelligently with the transformers.

\section{References}

Kazmi, H. et al. (2019) 'Electricity load-shedding in Pakistan: Unintended consequences, opportunities and policy recommendations', Energy Policy, 128, pp. 411-417.

Nebey, A. H. (2020) 'Automatic load sharing of distribution transformer for overload protection', BMC Research Notes, 13(1), pp. 1-6. doi: 10.1186/s13104-019-4880-1.

Shukla, A. et al. (2017) 'PLC Based Load Sharing System', IRJET, 4(2), pp. 41-43. Available at: https://issuu.com/irjet/docs/irjet-v4i208 (Accessed: 1 February 2021).

Suryawanshi, A. A. et al. (2019) 'Automatic Changeover System using PLC', International Journal of Engineering Science and Computing, 9(3), pp. 20888-20891. Available at: http://ijesc.org/ (Accessed: 1 February 2021). 